RESEARCH REPORT

\title{
Who you live with and where you live: setting the context for health using multiple membership multilevel models
}

\author{
Tarani Chandola, Paul Clarke, Richard D Wiggins, Mel Bartley
}

J Epidemiol Community Health 2005;59:170-175. doi: 10.1136/jech.2003.019539

See end of article for authors' affiliations

Correspondence to:

Dr T Chandola,

Department of

Epidemiology and Public

Health, University College

London, 1-19 Torrington

Place, London WC1E 6BT,

UK; tarani@public-health.

ucl.ac.uk

Accepted for publication 19 July 2004

Study objective: Previous studies into the effect of area of residence on individuals' health have not accounted for changing residency over time, although few people remain resident in the same area throughout their life. Furthermore, few studies of area effects on health have accounted for the clustering of health at the household level. These methodological problems may have led previous studies to under estimate or over estimate the size of area level effects. This study uses multiple membership multilevel models to investigate whether longitudinal analyses of area effects on health need to take account of clustering at the household level.

Setting and participants: A longitudinal survey (1991-1999) of a nationally representative sample of British households (5511 households with 10264 adult members).

Design: Two level (individuals within households or areas) and three level (individuals within households within areas) multiple membership models of SF-36 physical and mental health functioning scores at wave nine were analysed adjusting for age, gender, education, marital, employment, and smoking status from previous waves.

Results: Physical and mental health functioning seem to cluster within households. Accounting for changes in household membership over time increases estimates of the clustering in functioning at the household level. The clustering of functioning within area wards is reduced when the clustering within households and risk factors for functioning are taken into account.

Conclusions: Clustered sampling units within study designs should be taken account of in individual level analyses. Changes in these units over time should be accounted for in longitudinal analysis.

A number of studies have found evidence for area effects on health. ${ }^{1}$ The studies were based on multilevel analyses of how future health is associated with baseline measures of individual characteristics and area membership. Even accounting for compositional characteristics, people living in the same areas were found to share similar health.

One drawback of these studies is the failure to account for changing residency patterns on health. They assume a person's area membership remains the same over the study period. However, others ${ }^{2}$ argue that area differences in health need to be analysed not only in terms of the effects of the current area, but also in terms of the effect on health of where individuals lived in the past.

Recent advances in multilevel modelling now enable the formulation of models where individual membership of higher level units such as households and areas can change over time. ${ }^{3}{ }^{4}$ These multiple membership models allow for membership of different units at the higher (area) level to reflect geographical migration over the life course. Some argue that geographical inequalities in health are increasing in Britain, with richer areas getting healthier and more deprived areas getting less healthy. ${ }^{5}$ Over time, members of a particular area or neighbourhood may tend to become more similar in terms of their health. A similar argument could be made about the household level: as children leave their parent's households to set up their own families, members of households may become more similar in age and health. Previous research on area effects on health has not accounted for such mobility, and it remains to be established what effect this might have on estimates of area effects.

Previous research into contextual effects on health has also tended to ignore the impact of the household and its coresidents on a person's health. Some studies have concluded there are significant area effects on individual level health because the variance (in health) at the area level is significant, even after adjusting for a number of individual level characteristics. ${ }^{67}$ However, if the clustering of the health of individuals within areas is partly attributable to the clustering of individuals within households, then the omission of "household" as a level from the analysis could lead to misleading conclusions about the interpretation and importance of area effects on individual health. Although many studies into area level effects have used data from surveys where one adult is selected from each sampled household, some studies have used household samples to analyse area differences in health and related behaviours but failed to account for the clustering at the household level. ${ }^{8-10}$ Evidence from other studies points towards a much greater clustering of health within households compared with clustering within areas. ${ }^{611-13}$

Therefore, it is appropriate to examine the health of individuals in the context of the households and areas in which they live, using a three level multilevel model that accounts for changing household and area membership. We consider the following research questions:

(1) Is there evidence for clustering of health within households and within areas?

(2) Does the clustering of health within households explain, in part, the clustering of health within areas?

(3) How does taking account of individuals changing household/area membership affect the answer to question two?

Abbreviations: BHPS, British household panel survey; PCS, physical health component score; MCS, mental health component score; DIC, deviance information criterion; ICC, intraclass correlation 


\section{METHODS}

The British household panel survey (BHPS) is a longitudinal survey of adult members (age 16 and over) of a nationally representative sample of British households (5511 households with 10264 adult members). The initial survey was conducted in 1991 and subsequent annual surveys for the cohort were added to the original data. Further information on the methodology of the survey can be found in Taylor et al. ${ }^{14}$

\section{Outcome variable}

The short form (SF) 36 questionnaire was administered to the BHPS respondents for the first time at wave 9 (1999). The eight SF-36 domain scores were combined into two component scores-the physical (PCS) and mental (MCS) health component scores that reflect physical and mental health functioning. ${ }^{15}$

Explanatory variables included age, sex, household membership at waves 1 to 8 , area of residence at waves 1 to 8 , and risk factors for SF-36 health functioning (education, employment marital, and smoking status). ${ }^{16}{ }^{17}$ These were measured from the first wave of the BHPS data and missing values were supplemented from the next available wave. Around $42 \%$ of households at wave one were single person households and over $50 \%$ were households with two members. Members of the same household either share living accommodation or share one meal a day and have the same address as their only or main residence. Household leavers were defined if they were no longer a member of their household identified from the previous wave and were no longer living at the same address. Such household leavers were traced and the new members of the households they joined or created were added into the BHPS study. However, new entrants are not included in the analysis as they cannot be assigned membership of a wave one household or area, which is necessary for the multiple membership models.

Area of residence was identified at the electoral ward level using 1991 ward boundaries. Electoral wards vary in size and in this sample, ranged from having just one household (17\% of wards) to 10 or more households (around 20\% of wards).
A

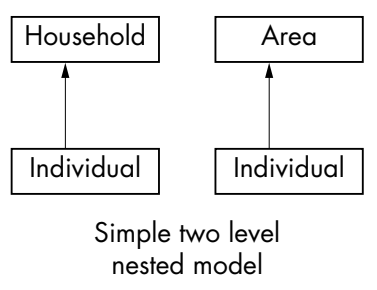

B

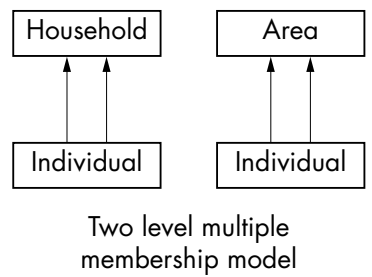

C

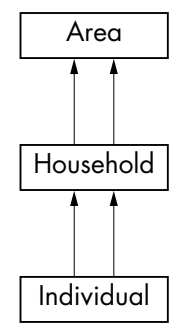

Three level multiple membership model
Figure 1 Classification diagrams for (A) "simple" two level nested model (B) two level multiple membership model (C) three level multiple membership model.

\section{Analysis}

A series of multilevel models were fitted for each outcome variable. To address research question 1, two "simple" two level models were considered; the simple model hierarchical structure is shown schematically in figure $1(\mathrm{~A})$. The first simple model has individuals nested in areas (membership defined at wave 1), permitting estimation of the random area level effects, ignoring the household level and changes in area membership. The second simple model has individuals nested within households (membership defined at wave 1), permitting estimation of the random household level effects, ignoring the area level and changes in household membership. To address research question 2, a simple three level model was also fitted, with individuals nested within households nested within areas.

Multilevel multiple membership models were used to address research question 3 by estimating the association between individual characteristics grouped within changing households or areas and health. A schematic representation for a two level multiple membership multilevel model is shown in figure $\mathrm{l}(\mathrm{B})$, and for a three level multiple membership model in figure $1(\mathrm{C})$. The random household or area effects are weighted by the length of time in residence in a household or area. Brown et $a^{3}$ give further details on multiple membership models. If the household or area level variance estimates change from a simple to multiple membership model, this suggests evidence for question 3.

Two sets of results are given for each of the models discussed above: unadjusted and adjusted for individual level explanatory characteristics. It is necessary for multilevel analysis of health outcomes to include individual level/ compositional risk factors for the outcome health variable. This allows for proper interpretation of inferences regarding contextual effects associated with the higher levels (either household or area levels in this case). It is possible that the individual level risk factors for poor health functioning may also affect household maintenance and dissolution and this may explain the apparent clustering of health functioning at the household or area levels.

The intraclass correlation (ICC) was used to measure the proportion of the total variance that is attributable to a specific level. All of the models considered here were fitted using Markov chain Monte Carlo (MCMC) techniques in the software package MLwiN. ${ }^{18}$ Thus, the Bayesian deviance information criterion (DIC) was used to calculate the relative fit of each model instead of the likelihood ratio test. The DIC is a measure of a model's overall fit, penalised for its parametric complexity. The DIC decreases as "significant" effects (both random and fixed) are added to the model; hence, a multiple membership model is an improvement on its corresponding two or three level multilevel model if it has a smaller DIC. ${ }^{3}{ }^{19}$

Single person households were included in the analysis because they contribute to estimation of the individual level explanatory characteristics in the fixed effects part of the model, even though they do not contribute to the estimates of household level variance. ${ }^{4} 20$

The research methods conform to the principles embodied in the Declaration of Helsinki.

\section{RESULTS}

Table 1 contains the distribution of people at each wave who said they had moved household since the previous wave. Between $1 \%-2 \%$ of BHPS respondents on whom there is complete information leave their households every year, and around $5 \%-6 \%$ of the respondents migrate to a different ward. Respondents who had died by wave nine were not entered into the analysis nor were they recorded as household or area "leavers". From table 1, it can further be seen 
Table 1 Wave on wave distribution of household leavers and area migrants BHPS waves one to eight, complete cases in all waves

\begin{tabular}{|c|c|c|c|c|c|c|c|}
\hline \multicolumn{8}{|c|}{ Whether left household from previous wave } \\
\hline Count & wave 2 & wave 3 & wave 4 & wave 5 & wave 6 & wave 7 & wave 8 \\
\hline No & 6086 & 6118 & 6142 & 6133 & 6142 & 6137 & 6716 \\
\hline Yes & 115 & 83 & 59 & 68 & 59 & 64 & 190 \\
\hline Total & 6201 & 6201 & 6201 & 6201 & 6201 & 6201 & 6906 \\
\hline \multicolumn{8}{|c|}{ Physical component score (PCS) \% } \\
\hline No & 48.9 & 48.9 & 49.0 & 48.9 & 48.9 & 48.9 & 49.0 \\
\hline Yes & 54.2 & 55.1 & 52.2 & 54.0 & 53.7 & 52.2 & 51.5 \\
\hline \multicolumn{8}{|c|}{ Mental component score (MCS) \% } \\
\hline No & 52.7 & 52.7 & 52.7 & 52.7 & 52.7 & 52.7 & 52.7 \\
\hline Yes & 51.9 & 52.3 & 54.7 & 51.6 & 50.1 & 53.2 & 53.5 \\
\hline \multicolumn{8}{|c|}{ Age (mean) } \\
\hline No & 44.1 & 44.1 & 44.0 & 44.0 & 44.0 & 44.0 & 44.0 \\
\hline Yes & 26.2 & 25.4 & 27.0 & 24.4 & 26.6 & 25.4 & 24.8 \\
\hline \multicolumn{8}{|c|}{ Whether left electoral ward from previous wave } \\
\hline \multicolumn{8}{|c|}{ Count } \\
\hline No & 5915 & 5836 & 5797 & 5883 & 5860 & 5811 & 6711 \\
\hline Yes & 286 & 365 & 404 & 318 & 341 & 390 & 195 \\
\hline Total & 6201 & 6201 & 6201 & 6201 & 6201 & 6201 & 6906 \\
\hline \multicolumn{8}{|c|}{ Physical component score (PCS) \% } \\
\hline No & 48.9 & 48.9 & 48.8 & 48.8 & 48.8 & 48.8 & 48.8 \\
\hline Yes & 50.0 & 50.9 & 51.9 & 51.9 & 51.7 & 51.0 & 51.4 \\
\hline \multicolumn{8}{|c|}{ Mental component score (MCS) \% } \\
\hline No & 52.7 & 52.8 & 52.8 & 52.7 & 52.7 & 52.8 & 52.7 \\
\hline Yes & 52.3 & 52.4 & 52.0 & 52.3 & 52.4 & 51.6 & 52.4 \\
\hline \multicolumn{8}{|c|}{ Age (mean) } \\
\hline No & 44.3 & 44.5 & 44.5 & 44.3 & 44.4 & 44.4 & 44.5 \\
\hline Yes & 34.4 & 34.1 & 33.8 & 35.8 & 34.3 & 34.7 & 33.9 \\
\hline
\end{tabular}

that household or area "leavers" tended to be younger than those who remained in their original household or area, and that these people tended to have better physical functioning, on average. However, household and area leavers and "stayers" did not differ much in terms of mental health functioning. Some of the most common reasons for leaving a household were separation/divorce, going to college/university, marriage/cohabitation, and setting up home.

Table 2 contains the variance (random effects) in the SF-36 mental health score (MCS) from a series of multilevel models. We have examined the impact that each modelling strategy has on the magnitude of the variance components at each level to illustrate the effect of health clustering. The "unadjusted" models contain a constant term only and the "adjusted" models are adjusted for age, gender, marital, employment, and smoking status (see table 4 for fixed effect estimates). The base model is a single level model that does not account for clustering in MCS scores at the household or area level and hence no random effects estimates are given.

Consider first the unadjusted results. The simple two level model allows clustering of individuals within households (as defined at wave 1), but ignores any clustering in MCS scores at the area level. This improves the fit of the model compared with the base model (the DIC statistic is smaller). Furthermore, the estimated household level variance is statistically significant and different from zero. From the ICC, around $24 \%$ of the total variance in MCS is at the household level. Compared with the simple model, the multiple household membership model results in a further reduction in the DIC statistic, indicating that the latter is a better fit. The household ICC increases slightly to $25 \%$.

The next simple model, "individuals within wave 1 areas", ignores any clustering in MCS scores at the household level, and gives an improved fit compared with the base model.

Table 2 Unadjusted and adjusted random effects estimates of a series of multilevel analyses of mental component scores (MCS)

\begin{tabular}{|c|c|c|c|c|c|}
\hline \multirow{2}{*}{$\begin{array}{l}\text { Unadjusted } \\
\text { Model }\end{array}$} & \multicolumn{2}{|c|}{ Household (HH) } & \multicolumn{2}{|l|}{ Area } & \multirow[b]{2}{*}{ DIC } \\
\hline & Variance (SE) & ICC $(95 \% \mathrm{CI})$ & Variance (SE) & ICC $(95 \% \mathrm{CI})$ & \\
\hline Base model-individual (ind) level & - & - & - & - & 38777 \\
\hline ind within wave $1 \mathrm{HH}$ & $19.12(1.84)$ & $0.24(0.21$ to 0.26$)$ & - & - & 38408 \\
\hline ind within multiple $\mathrm{HH}$ & $19.99(1.83)$ & $0.25(0.23$ to 0.27$)$ & - & - & 38389 \\
\hline ind within wave 1 areas & - & - & $4.55(0.79)$ & $0.06(0.04$ to 0.08$)$ & 38673 \\
\hline ind within multiple areas & - & - & $3.49(0.74)$ & 0.04 (0.03 to 0.06$)$ & 38708 \\
\hline ind within wave $1 \mathrm{HH}$ within wave 1 areas & $15.86(1.79)$ & $0.20(0.17$ to 0.22$)$ & $3.01(0.81)$ & $0.04(0.00$ to 0.05$)$ & 38391 \\
\hline ind within multiple $\mathrm{HH}$ within wave 1 areas & $17.75(1.97)$ & $0.23(0.20$ to 0.25$)$ & $1.94^{*}(0.66)$ & $0.03(0.00$ to 0.04$)$ & 37949 \\
\hline \multicolumn{6}{|l|}{ Adjusted } \\
\hline Base mode-individual (ind) level & - & - & - & - & 38553 \\
\hline ind within wave $1 \mathrm{HH}$ & $17.67(1.86)$ & $0.24(0.21$ to 0.26$)$ & - & - & 38194 \\
\hline ind within multiple $\mathrm{HH}$ & $18.70(1.91)$ & $0.25(0.22$ to 0.27$)$ & - & - & 38176 \\
\hline ind within wave 1 areas & - & - & $3.92(0.78)$ & 0.05 (0.04 to 0.07$)$ & 38465 \\
\hline ind within multiple areas & - & - & $2.63(0.69)$ & $0.04(0.02$ to 0.05$)$ & 38509 \\
\hline ind within wave $1 \mathrm{HH}$ within wave 1 areas & $15.31(1.89)$ & $0.21(0.17$ to 0.23$)$ & $2.39(0.75)$ & $0.03(0.01$ to 0.04$)$ & 38177 \\
\hline ind within multiple $\mathrm{HH}$ within wave 1 areas & $17.19(1.95)$ & $0.23(0.20$ to 0.25$)$ & $1.40^{*}(0.59)$ & $0.02(0.01$ to 0.03$)$ & 38170 \\
\hline
\end{tabular}


Table 3 Unadjusted and adjusted random effects estimates of a series of multilevel analyses of physical component scores (PCS)

\begin{tabular}{|c|c|c|c|c|c|}
\hline \multirow{2}{*}{$\begin{array}{l}\text { Unadjusted } \\
\text { Model }\end{array}$} & \multicolumn{2}{|l|}{ Household (HH) } & \multicolumn{2}{|l|}{ Area } & \multirow[b]{2}{*}{ DIC } \\
\hline & Variance (SE) & ICC $(95 \% \mathrm{CI})$ & Variance (SE) & ICC $(95 \% \mathrm{CI})$ & \\
\hline Base model-individual (ind) level & - & - & - & - & 41170 \\
\hline ind within wave $1 \mathrm{HH}$ & $31.32(3.22)$ & $0.26(0.22$ to 0.27$)$ & - & - & 40782 \\
\hline ind within multiple $\mathrm{HH}$ & $35.87(3.17)$ & $0.29(0.26$ to 0.30$)$ & - & - & 40637 \\
\hline ind within wave 1 areas & - & - & $7.08(1.33)$ & 0.06 (0.04 to 0.07$)$ & 41080 \\
\hline ind within multiple areas & - & - & $8.39(1.39)$ & $0.07(0.05$ to 0.08$)$ & 41003 \\
\hline ind within wave $1 \mathrm{HH}$ within wave 1 areas & $26.57(2.81)$ & $0.22(0.19$ to 0.24$)$ & $4.63(1.27)$ & $0.04(0.02$ to 0.05$)$ & 40765 \\
\hline $\begin{array}{l}\text { ind within multiple } \mathrm{HH} \text { within wave } 1 \text { areas } \\
\text { Adjusted }\end{array}$ & $31.79(3.14)$ & $0.26(0.24$ to 0.28$)$ & $3.70 *(1.21)$ & 0.03 (0.01 to 0.04$)$ & 40610 \\
\hline Base model-individual (ind) level & - & - & - & - & 39458 \\
\hline ind within wave $1 \mathrm{HH}$ & $10.33(2.54)$ & $0.10(0.06$ to 0.13$)$ & - & - & 39365 \\
\hline ind within multiple $\mathrm{HH}$ & $13.31(2.43)$ & $0.15(0.10$ to 0.18$)$ & - & - & 39318 \\
\hline ind within wave 1 areas & - & - & $3.36 *(0.97)$ & $0.04(0.02$ to 0.06$)$ & 39411 \\
\hline ind within multiple areas & - & - & $3.30(0.88)$ & $0.04(0.02$ to 0.05$)$ & 39412 \\
\hline ind within wave $1 \mathrm{HH}$ within wave 1 areas & $8.48 *(2.41)$ & $0.09(0.05$ to 0.13$)$ & $2.26^{*}(1.18)$ & $0.03(0.00$ to 0.04$)$ & 39349 \\
\hline ind within multiple $\mathrm{HH}$ within wave 1 areas & $11.82(2.36)$ & $0.13(0.09$ to 0.16$)$ & $1.92 *(0.77)$ & 0.02 (0.01 to 0.03 ) & 39299 \\
\hline
\end{tabular}

Furthermore, the estimated ward level variance is significant-around 5\% of the total variance in MCS is at the ward level. When we account for people migrating to different wards, the area ICC reduces to $3 \%$. However, the DIC statistic for the multiple membership model increases, indicating it offers no improvement over the simple two level model.

The variances estimated at the household and ward levels for the simple three level model are both statistically significant. When we compare this model with the three level multiple membership model, which accounts for changing household membership (but not migration to different areas), the second model is the better fit. The area
ICC decreases to $3 \%$, while the household ICC increases to $23 \%$. However, the estimated variance at the area level could not be reliably estimated; this issue is discussed further on.

The next section of the table examines the same models for MCS, but adjusted for the fixed effects age, gender, marital, employment, and smoking status. The results are similar to the ones described above. Comparing the two level simple and multiple household membership models, the DIC statistic indicates that the second is better fitting. In contrast, comparing the two level simple and multiple area membership models, the DIC statistic indicates that the first is the better fitting model. When we compare the three level simple

\begin{tabular}{|c|c|c|c|c|c|}
\hline \multirow[b]{2}{*}{ Explanatory variables } & \multicolumn{2}{|l|}{ PCS } & \multicolumn{2}{|l|}{ MCS } & \multirow[b]{2}{*}{ Number } \\
\hline & Estimate & SE & Estimate & SE & \\
\hline \multicolumn{6}{|l|}{ Age } \\
\hline $18-24^{*}$ & 0.00 & & 0.00 & & 636 \\
\hline $25-34$ & -0.61 & 0.51 & 0.22 & 0.46 & 1335 \\
\hline $35-44$ & -1.52 & 0.53 & 0.04 & 0.47 & 1360 \\
\hline $45-54$ & -4.61 & 0.57 & 1.23 & 0.50 & 1047 \\
\hline $55-64$ & -5.51 & 0.65 & 2.83 & 0.56 & 779 \\
\hline $65-74$ & -10.02 & 0.82 & 1.25 & 0.73 & 653 \\
\hline $75+$ & -14.77 & 1.07 & 1.00 & 0.94 & 250 \\
\hline \multicolumn{6}{|l|}{ Gender } \\
\hline$M^{*}{ }^{*}$ & 0.00 & & 0.00 & & 2742 \\
\hline Women & -1.54 & 0.27 & -1.86 & 0.23 & 3318 \\
\hline \multicolumn{6}{|l|}{ Marital status } \\
\hline Married* ${ }^{*}$ & 0.00 & & 0.00 & & 4043 \\
\hline Living as couple & -0.18 & 0.55 & 0.74 & 0.50 & 373 \\
\hline Widowed & -0.72 & 0.55 & -0.06 & 0.50 & 412 \\
\hline Divorced & -1.36 & 0.49 & -1.07 & 0.52 & 262 \\
\hline Separated & -0.30 & 1.00 & -2.17 & 0.92 & 108 \\
\hline \multirow{2}{*}{\multicolumn{6}{|c|}{$\begin{array}{l}\text { Education } \\
\text { Eded }\end{array}$}} \\
\hline & & & & & \\
\hline Degree $^{*}$ & 0.00 & & & & 517 \\
\hline A level or equivalent & 0.05 & 0.49 & & & 1142 \\
\hline O level or equivalent & -0.46 & 0.48 & & & 1888 \\
\hline None & -2.21 & 0.50 & & & 2455 \\
\hline \multicolumn{6}{|l|}{ Current smoker } \\
\hline $\mathrm{No}^{*}$ & 0.00 & & 0.00 & & 4350 \\
\hline Yes & -1.08 & 0.31 & -1.52 & 0.28 & 1710 \\
\hline \multicolumn{6}{|l|}{ Employment status } \\
\hline Employed* ${ }^{*}$ & 0.00 & & 0.00 & & 3999 \\
\hline Unemployed & -1.05 & 0.65 & -1.59 & 0.58 & 267 \\
\hline Retired & -1.56 & 0.61 & -0.32 & 0.55 & 947 \\
\hline Family care & -1.16 & 0.44 & -0.85 & 0.40 & 689 \\
\hline Long term sick/disabled & -16.52 & 0.83 & -5.88 & 0.75 & 155 \\
\hline
\end{tabular}


model with the three level multiple membership model, the second is the better fitting model. Furthermore, the estimated variance at the area level reduces and cannot be reliably estimated.

Similar analyses were carried out on physical functioning - the physical component score (PCS) — shown in table 3. A similar pattern of results emerged as was found for MCS. Among the unadjusted two and three level models, there was significant clustering in PCS scores at the household and area levels. Comparing the adjusted two level models, the multiple household membership models improved the fit compared with the simple model with a corresponding increase in the household ICC. However, taking area migration into account did not improve the fit over the simple model. The three level model-individuals within changing households within wave 1 areas-was a better fitting model compared with the simple three level model. However, the estimated variance at the area level could again not be reliably estimated.

All the MCMC results were checked by inspecting the Raftery-Lewis quantiles and the mean Brooks-Draper statistic. Each MCMC chain ran for 50000 iterations and these statistics calculated for the fixed effects and the random effects. The results indicated that the number of iterations was sufficient for all parameters bar the area level variance in the three level multiple membership models, where the Raftery-Lewis statistic indicated that a longer chain was required. However, running very long chains made little difference to the results discussed above. Different starting values were also used but did not change the pattern of results reported above.

The interpretation of the random part of the models (in tables 2 and 3 ) is considered most relevant to the substance of our investigation. However, the coefficients in the fixed part of the three level multiple membership model are shown in table 4. With the exception of age and education, the fixed effects were similar for both mental (MCS) and physical health functioning (PCS). Women, the divorced, current smokers, and the non-employed had poorer physical and mental health functioning compared with men, the married, non-smokers, and the employed respectively. Older people were more likely to have poorer physical functioning and better mental functioning. Low education was associated with poorer physical functioning but not significantly associated with poorer mental functioning.

\section{DISCUSSION}

\section{Summary of results}

There is evidence that mental and physical health functioning clusters at both the area and the household level. People living within the same areas and people from the same

\section{Key points}

- Health functioning seems to cluster within households

- Taking account of changes in household membership increases the clustering of physical and mental health functioning at the household level

- The apparent clustering of health functioning at the ward level may be partly explained by a combination of compositional risk factors and the clustering of health at the household level

- Studies using statistical designs that select clusters as sampling units should take account of such units in any subsequent analyses. households share similar mental and physical health functioning. Furthermore, accounting for changing household membership results in increased estimates of household level variance. In contrast, accounting for migration to different areas tended to decrease the area level variance in MCS. For both mental and physical health, the variance of health at the area level reduced by half after accounting for age, gender, education, marital, smoking, and employment status, and also household level clustering. Taking account of changing household membership seems to affect the area level variance.

A possible explanation of increased variability between households because of changes in household membership is that household leavers tend to be younger (such as children leaving their parental home), which could make the original household more homogenous and thus increase variation between households. However, a similar process was not observed for people who moved away from their original residential areas; although migrants tend to be younger and have better physical functioning, this did not result in greater homogeneity in health within the original areas. It should be noted that the comparatively low rate of migration $(1 \%-2 \%)$ is this sample makes such effects hard to detect.

This study also suggests that any investigation of social variations in health needs to take full account of household membership and characteristics. Multilevel modelling of individuals nested within households has shown people living in households share similar self rated health status, even after adjusting for a number of individual characteristics. ${ }^{621}$ There are a number of plausible mechanisms that could result in the clustering of health within households. Nutritional and hygienic behaviours may affect the health of all family and household members ${ }^{22}$; physical characteristics of the household such as damp may affect the health of all household members ${ }^{23}$; characteristics of one household member (such as their employment or health status) can affect the health of other household members. ${ }^{24}$ The findings from this study suggest that an examination of household contextual mechanisms for explaining the clustering of health within households is becoming increasingly important.

There are a number of caveats to be considered when interpreting these results. Causal conclusions may not be drawn from the results about household effects on health. The variance at the household level observed in the analysis may be accounted for by individual level characteristics not included in the model. Secondly, electoral wards may not be the appropriate area level to measure neighbourhood effects on health. Other studies have used smaller geographical units of analyses to find significant clustering of health at the area level. ${ }^{1}$ It is possible that health may cluster within other subneighbourhood contexts such as work places or schools. Thirdly, the analyses only examined respondents on whom there was complete information at all waves of the BHPS. Selective drop out from the study may have biased these results. However, cross sectional analysis of the wave nine BHPS data showed similar patterns of results to the ones presented in this paper-the explanatory variables had similar associations with health functioning and the latter showed similar patterns of clustering at the household and

\section{Policy implications}

Contextual effects on health at the household level may need to be assessed before recommending policies on improving health through focusing on larger units of aggregation, like neighbourhoods, wards, or districts. 
ward levels. This suggests that attrition from the original sample did not substantially bias the results.

To conclude, the results from this study highlight the importance of adding a household level and taking account of movement between areas and households when investigating area effects on health. Wherever sample designs select clusters as sampling units, such units should be taken account of in any subsequent analyses and changes in these units over time should be accounted for in longitudinal analysis.

\section{ACKNOWLEDGEMENTS}

The data and tabulations used in this publication were made available through The ESRC Data Archive. The data were originally collected by the ESRC Research Centre on Micro-Social Change at the University of Essex. Neither the original collectors of the data nor the archive bear any responsibility for the analyses or interpretations presented here. The authors would like to thank the referees of the original manuscript for their helpful comments and suggestions.

\section{Authors' affiliations}

T Chandola, P Clarke, M Bartley, Department of Epidemiology and Public Health, University College London, UK

R D Wiggins, Department of Sociology, City University, London, UK

Funding: this work was funded as part of the Medical Research Council's "Health of the Public" initiative (grant number: 9900586). The authors also work on the Whitehall II study, which is supported by grants from the Medical Research Council, ESRC (RES-000-22-0290), British Heart Foundation; Health and Safety Executive; Department of Health; National Heart Lung and Blood Institute (HL36310), US, NIH: National Institute on Aging (AG13196), US, NIH; Agency for Health Care Policy Research (HS06516); and the John D and Catherine T MacArthur Foundation Research Networks on Successful Midlife Development and Socio-economic Status and Health. Tarani Chandola is also supported by an ESRC grant (RES-000-22-0290).

Conflicts of interest: none declared.

\section{REFERENCES}

1 Pickett K, Pearl M. Multilevel analyses of neighbourhood socioeconomic context and health outcomes: a critical review. J Epidemiol Community Health 2001;55:111-22.

2 Orford S, Dorling D, Mitchell R, et al. Life and death of the people of London: an historical GIS of Charles Booth's inquiry. Health Place 2002;8:25-35.

3 Browne W, Goldstein H, Rabash J. Multiple membership multiple classification (MMMC) models. Statistical Modelling 2001;1:103-24.
4 Goldstein H, Rasbash J, Browne W, et al. Multilevel models in the study of dynamic hosuehold structures. European Journal of Population 2000; 16:373-88

5 Shaw M, Dorling D, Gordon D, et al. The widening gap: health inequalities and policy in Britain. Bristol: Policy Press, 1999.

6 Pampalon R, Duncan C, Subramaniam S, et al. Geographies of health perception in Quebec: a multilevel perspective. Soc Sci Med 1999;48: 1483-90.

7 Jones K, Duncan C. Individuals and their ecologies: analysing the geography of chronic illness within a multilevel modelling framework. Health Place 1995; 1:27-40.

8 Boreham R, Stafford M, Taylor R. Social capital and health: health survey for England 2000. London: The Stationery Office, 2002.

9 Hedges B, di Salvo P, Purdon S. Health variations by 'ACORN' area classifications: health survey for England 1996. London: The Stationery Office, 1998.

10 Twigg L, Moon G, Jones K. Predicting small-area health-related behaviour: a comparison of smoking and drinking indicators. Soc Sci Med 2000;50:1109-20.

11 Weich S, Holt G, Twigg L, et al. Geographic variation in the prevalence of common mental disorders in Britain: a multilevel investigation. Am J Epidemiol 2003; 157:730-7

12 Weich S, Twigg L, Holt G, et al. Contextual risk factors for the common mental disorders in Britain: a multilevel investigation of the effects of place. J Epidemiol Community Health 2003;57:616-21.

13 Subramanian S, Delgado I, Jadue L, et al. Income inequality and health: multilevel analysis of Chilean communities. J Epidemiol Community Health 2003;57:844-8.

14 Taylor M, Brice J, Buck N, et al. British household panel survey user manual volume A: introduction, technical report and appendices. Colchester: University of Essex, 1999.

15 Ware J, Kosinsky S. SF-36 physical and mental health summary scales: a user's manual. Boston, MA: The Health Institute, 1994.

16 Hemingway H, Nicholson A, Marmot M. The impact of socioeconomic status on health functioning as assessed by the SF-36 questionnaire: the Whitehall II study. Am J Public Health 1997:87:1484-90.

17 Sullivan M, Karlsson J. The Swedish SF-36 health survey III. evaluation of criterion-based validity results from normative population. J Clin Epidemiol 1998;51:1105-13.

18 Browne W. MCMC estimation in MLWin (version 2.0). London: Institute of Education, University of London, 2003.

19 Spiegelhalter D, Best N, Carlin B, et al. Bayesian measures of model complexity and fit. Journal of the Royal Statistical Society, Series B 2002;64:583-639.

20 Goldstein H. Multilevel statistical models. 3rd ed. London: Arnold, 2003.

21 Chandola T, Bartley M, Wiggins R, et al. Social inequalities in health by individual and household measures of social position in a cohort of healthy people. J Epidemiol Community Health 2003;57:56-62

22 Kuate-Defo B, Diallo K. Geography of child mortality clustering within African families. Health Place 2002:8:93-117.

23 Macintyre S, Ellaway A, Hiscock R, et al. What features of the home and the area might help to explain observed relationships between housing tenure and health? Evidence from the west of Scotland. Health Place 2003;9:207-18.

24 Nieboer A, Schulz R, Matthews K, et al. Spousal caregivers' activity restriction and depression: a model for changes over time. Soc Sci Med 1998:47:1361-71. 